\title{
Attitudes of undergraduate university women towards HPV vaccination: a cross-sectional study in Ottawa, Canada
}

\author{
Rachel Fernandes ${ }^{1,2^{*}} \mathbb{D}$, Beth K. Potter ${ }^{1,3}$ and Julian Little
}

\begin{abstract}
Background: Persistent infection with certain subtypes of human papillomavirus (HPV) is a necessary cause of cervical cancer. Although two prophylactic vaccines have been licensed in Canada against cancerous subtypes of HPV, vaccine uptake has been lower than anticipated. The primary objective of this study was to determine the acceptability of catch-up HPV vaccination to undergraduate university women under the age of 25 , by assessing their perceptions of HPV vaccination.

Methods: A total of 401 University of Ottawa female undergraduate students participated in a cross-sectional bilingual web-based survey on HPV vaccination.

Results: The prevalence of immunization with at least 1 HPV vaccine dose was $49 \%$ in the study population. Although the overall attitude of study participants towards the vaccine was positive, vaccinated respondents had a more favourable attitude towards the vaccine than non-vaccinated respondents. Approximately half of the non-vaccinated respondents were interested in receiving the vaccine at some point in the future. The primary barriers to HPV vaccination identified by non-vaccinated respondents were lack of knowledge about the vaccines, potential vaccine side effects and cost of vaccination. Multivariable analysis comparing non-vaccinated respondents who intended to be vaccinated and those who did not suggests that the former group had a more favourable attitude towards the vaccine and would be influenced by doctor recommendation.

Conclusions: Offering HPV vaccination for women aged 18 to 25 provides an opportunity to address suboptimal vaccination coverage in the population and may reduce health inequities demonstrated by variations in cervical cancer incidence within jurisdictions.
\end{abstract}

Keywords: HPV, Vaccination, Sexual health, Sexual behaviour

\section{Background}

Cervical cancer is the second most common cancer afflicting women and the third leading cause of cancer mortality among women worldwide $[1,2]$. This disease affects more than 530,000 women annually, $85 \%$ of whom live in the developing world [2]. Persistent infection with Human papillomavirus (HPV) has been established as the primary cause of cervical cancer, accounting for upwards of $90 \%$ of

\footnotetext{
* Correspondence: rachel.fernandes@mail.mcgill.ca

${ }^{1}$ School of Epidemiology and Public Health, University of Ottawa, Ottawa, Canada

${ }^{2}$ Faculty of Medicine, School of Epidemiology and Public Health, University of Ottawa, 600 Peter Morand Crescent, Room 207G, Ottawa On K1G 5Z3,

Canada

Full list of author information is available at the end of the article
}

all cervical cancer cases [3]. The vast majority of HPV infections are asymptomatic or sub-clinical, which has contributed to the rapid transmission and spread of the virus $[4,5]$.

HPV infections are so commonly transmitted that nearly $75 \%$ of Canadian adults are infected with the virus at some point in their life [6] while the highest rates of infection are in the population under the age of 24 [6].

Three different HPV vaccines have been approved for use in Canada. Cervarix has been approved for females only, while Gardasil has been approved for both sexes. Both vaccines protect against high-risk HPV types 16

(c) The Author(s). 2018 Open Access This article is distributed under the terms of the Creative Commons Attribution 4.0 International License (http://creativecommons.org/licenses/by/4.0/), which permits unrestricted use, distribution, and reproduction in any medium, provided you give appropriate credit to the original author(s) and the source, provide a link to the Creative Commons license, and indicate if changes were made. The Creative Commons Public Domain Dedication waiver (http://creativecommons.org/publicdomain/zero/1.0/) applies to the data made available in this article, unless otherwise stated. 
and 18, which together account for $70 \%$ of invasive cervical cancer cases [7]. Gardasil also provides immune protection to types 6 and 11, which cause genital warts. Although a nine-valent vaccine, Gardasil 9, is now available [8], only the quadrivalent Gardasil vaccine was in use at the time of the study. Though initially approved as a three-dose schedule, the new recommendation for immunocompetent girls aged 9-14 for both vaccines is a two-dose schedule, which was approved in July 2014 [9]. The potential advantages of HPV vaccination include prevention of HPV infection, cervical cancer and in the case of Gardasil, genital warts [10, 11]. Although these vaccines are most effective prior to onset of sexual activity, they can still be given to women who are sexually active, since it is rare for women to be infected with all vaccine-covered viral strains [12]. Furthermore, Cervarix offers cross-protection to additional oncogenic strains HPV-31, 33 and 45, while Gardasil may also offer cross-protection against strain $31[3,13]$.

Health Canada licensed the use of Gardasil in 2006 [14] and allocated $\$ 300$ million to provinces and territories in 2007 to promote HPV vaccination in young girls [15]. The bivalent vaccine, Cervarix, was licensed for use in girls and women aged 10 to 25 in 2010 [16] (though now the recommendation is females aged 9 through 26), while the quadrivalent vaccine Gardasil has been approved for females aged 9 to 45 [12].

The province of Ontario offered HPV vaccination to girls in grade 8 through school programs at no cost to girls and their families. Despite an expectation from the Canadian government that vaccine coverage would be $80 \%$ for eligible girls in the first 2 years of vaccination, by the end of 2009 in Ontario, only $56.6 \%$ of eligible girls had received the first dose of the three dose vaccine series [15]. Of this proportion, $85.3 \%$ had received all three doses of the vaccine, resulting in an overall vaccine uptake of $48.3 \%$ in Ontario [15]. This uptake rate is insufficient to ensure herd immunity, which requires coverage of $80 \%$ of the population [17].

In addition to low vaccine uptake rates through Ontario school programs, many women did not meet the age criteria to benefit from free vaccination when it was initially recommended in 2007 , as only girls in the eighth grade were initially targeted [18]. Thus, a sizeable number of Ontario women currently over the age of 18 years may benefit from being offered a HPV vaccine. To inform the current and any future catch-up HPV vaccination programs for young adult women in Ontario, it is therefore important to study women in this age group to assess their willingness to obtain the vaccine and factors associated with potential uptake.

The goal of this study was to determine the perceptions of women in university in Ottawa, aged 18 to 25, about the HPV vaccines. University women were chosen as the study population since as a well-educated subset of the population, any problems incurred with accepting or understanding the vaccine could be indicative of broader problems. Further, this population is diverse because Ottawa is a cosmopolitan city with substantial recent immigration from multiple countries [19]. Specific objectives were to:

1. Estimate the proportion of women in this age group who have been vaccinated with a HPV vaccine;

2. Estimate the proportion of women who would be interested in receiving the vaccine, among those who have not been vaccinated; and

3. Determine the main barriers that prevent and factors that promote HPV vaccination.

\section{Methods}

We conducted a cross-sectional study by means of a web-based survey. Undergraduate women between the ages of 18 and 25 who attended the University of Ottawa during the winter semester of 2013 were eligible for the study. We identified administrative, faculty, and student association contacts for a range of faculties and departments across the university and approached them to ask whether they would agree to administer our survey. Those who agreed were responsible for directly contacting their students using already compiled electronic lists that were inclusive of all students in a given faculty or department.

Students from one faculty and one department were contacted three times while the remaining potential participants were contacted once via email. These emails contained links to the web-based survey and were distributed in both English and French, as the University is bilingual.

The instrument, a study-specific bilingual questionnaire available on the Fluid Surveys web platform, was developed using previously published instruments [20, 21] and original questions (See Additional file 1 and Additional file 2). The questionnaire followed one of two automated branches, depending on the vaccination status of the participant. It had a total of 35 questions. The questionnaire assessed attitude towards receiving the HPV vaccine, beliefs about HPV vaccination, intentions to receive or complete the vaccine series, barriers to vaccination, factors that promote vaccine uptake and knowledge. The Theory of Planned Behaviour (TPB) [22] was used to design questions for the sections of the questionnaire pertaining to attitudes, beliefs and intentions toward HPV vaccination. The TPB has previously been used to predict health related behaviours in university-aged populations 
$[21,23]$. According to the theory, intention is the best predictor of behaviour. Intention itself is predicted by attitude toward a specific behaviour, subjective or social norms about the behaviour and one's perception of their own control over the specific behaviour [22]. Subjective norms represent perceived social pressure to participate in the behaviour. The questionnaire assessed these concepts through a series of seven-point Likert scales, to assign a quantitative value to each construct. As a measure of overall attitude toward vaccination, the mean score of a series of four behavioural belief variables (defined as a person's belief about the consequences of specific behaviour, particularly HPV vaccination) was taken. A lower score represented a more positive attitude toward the vaccine series, while a higher score indicated an unfavourable attitude. The primary outcomes of the study were the proportion of participants who were vaccinated against HPV and the intention of non-vaccinated participants to receive the vaccine series. Being vaccinated against $H P V$ was defined as having received a minimum of one vaccine dose of either HPV vaccine.

The data from the questionnaire were analyzed using descriptive statistics, including means and standard deviations for continuous variables and proportions with their associated 95\% confidence intervals for categorical variables. Subgroup analysis using univariable linear regression was used to compare the respondents who intended to be vaccinated against HPV at some point in the future with those who did not intend to be vaccinated in the future. Multivariable logistic regression was conducted to identify predictors of intended acceptance of HPV vaccination by assessing the differences between these two subpopulations. Variables representing the three pillars of the TPB, attitude, subjective norms and perceived behavioural control were included as predictors in the regression model, in addition to other participant characteristics which were significant at a 0.05 level when modelled individually against the outcome. Demographic characteristics previously associated with HPV vaccination in the literature were included in the final logistic regression model in order to control for possible confounding [21]. The database is available as an Additional file (see Additional file 3).

We handled item-missing data by casewise deletion, excluding participants who did not complete the first section of the questionnaire, including HPV vaccination status, attitudes towards the vaccine and intentions towards future vaccination. Statistical analyses were conducted using SAS 9.3.

This study was approved by the Ottawa Hospital Research Ethics Board (20130038-01H). Written informed consent was completed online prior to beginning the survey.

\section{Results}

\section{Participants}

Of the 2398 undergraduate women from four faculties (Arts, Social Sciences, Science and Health Sciences) who were invited to participate in this study, 378 completed the full questionnaire, while 23 others completed at least its first section. Approximately $15 \%$ of these respondents completed the survey in French. The study's response rate was estimated to be $17 \%$.

\section{Descriptive data}

Table 1 describes the general demographics of the study participants. The average age of study participants was 20.4, while the median ages for the vaccinated and non-vaccinated cohorts were 20 and 21 years, respectively. This study included women who had lived in 8 different Canadian provinces and several countries, and includes several ethnicities.

Of the 401 study participants, 196 (48.88\%) had received at least one dose of the HPV vaccine series. Of this subset, $57.65 \%$ (113) had received all three doses, while 13 (6.63\%) and 31 (15.81\%) respondents had received one and two doses of the vaccine respectively; nearly $20 \%$ (38) of the respondents were unsure of the number doses they had received.

\section{Intentions toward vaccination}

From the vaccinated cohort, 142 women (73.2\%) specified that they had already received the whole series, although only 113 indicated they had received 3 vaccine doses (Fig. 1). Only 34 of the women who had not received all 3 doses intended to complete the vaccine series in the time frame scheduled. Two women indicated they would not be completing the series. Nearly $50 \%(n=99)$ of the women in the unvaccinated group reported that they intended to be vaccinated at some point in the future.

\section{Attitudes towards HPV vaccination}

Overall, the participants in this study had positive perceptions about HPV vaccination, though vaccinated women had more favourable views toward the vaccine. Figure 2 illustrates the differences based on five Likert scales, which combined, provided a cumulative value to describe an overall attitude towards receiving the vaccine.

Sub-analyses of overall attitudes towards the vaccine series between the vaccinated and unvaccinated groups indicated that these results did not significantly differ among ethnicities, with the exception of vaccinated white women, who had significantly more positive views towards accepting the vaccine than white non-vaccinated women $(p<0.0001)$. Both Canadian-born and immigrant vaccinated women also had significantly more favourable views than their non-vaccinated counterparts $(p<0.0001$ and $p=0.04$, respectively). 
Table 1 Participant characteristics by vaccination status

\begin{tabular}{|c|c|c|c|c|}
\hline \multirow[t]{2}{*}{ Characteristic } & \multicolumn{2}{|c|}{$\begin{array}{l}\text { Vaccinated } \\
(n=196)\end{array}$} & \multicolumn{2}{|c|}{$\begin{array}{l}\text { Not vaccinated } \\
(n=205)\end{array}$} \\
\hline & $N$ & $\%$ & N & $\%$ \\
\hline \multicolumn{5}{|l|}{ Age } \\
\hline$\leq 19$ & 77 & 39.29 & 44 & 21.46 \\
\hline $20-21$ & 73 & 37.24 & 93 & 45.37 \\
\hline $22-23$ & 34 & 17.35 & 36 & 17.56 \\
\hline$\geq 24$ & 3 & 1.53 & 18 & 8.78 \\
\hline Missing & 9 & 4.59 & 14 & 6.83 \\
\hline \multicolumn{5}{|l|}{ Faculty } \\
\hline Arts & 9 & 4.59 & 10 & 4.88 \\
\hline Health Sciences & 17 & 8.67 & 13 & 6.34 \\
\hline Science & 145 & 73.98 & 147 & 71.71 \\
\hline Social Sciences & 16 & 8.16 & 20 & 9.76 \\
\hline Missing & 9 & 4.59 & 15 & 7.32 \\
\hline
\end{tabular}

Ethnicity

$\begin{array}{lllll}\text { White } & 144 & 73.47 & 115 & 56.10 \\ \text { Chinese } & 6 & 3.06 & 12 & 5.85 \\ \text { Black } & 8 & 4.08 & 15 & 7.32 \\ \text { Other } & 28 & 14.29 & 46 & 22.44 \\ \text { Missing } & 10 & 5.10 & 17 & 8.29\end{array}$

Province or Country of Residence before University of Ottawa

$\begin{array}{lllll}\text { Ontario } & 152 & 77.55 & 156 & 76.10 \\ \text { Quebec } & 22 & 11.22 & 15 & 7.32 \\ \text { Other Canadian Provinces } & 7 & 3.57 & 12 & 5.85 \\ \text { Outside Canada } & 6 & 3.06 & 7 & 3.41 \\ \text { Missing } & 9 & 4.59 & 15 & 7.32 \\ \text { Canadian Born } & & & & \\ \text { Yes } & 164 & 83.67 & 154 & 75.12 \\ \text { No } & 24 & 12.24 & 35 & 17.07 \\ \text { Missing } & 8 & 4.08 & 16 & 7.80\end{array}$

Ever had Sex

$\begin{array}{lllll}\text { Yes } & 140 & 71.43 & 124 & 60.49 \\ \text { No } & 48 & 24.49 & 63 & 30.73 \\ \text { Missing } & 8 & 4.08 & 18 & 8.78\end{array}$

Pap Smear

$\begin{array}{lllll}\text { More than 1 } & 68 & 34.69 & 57 & 27.80 \\ \text { Once } & 35 & 17.86 & 25 & 12.20 \\ \text { None } & 81 & 41.33 & 103 & 50.24 \\ \text { Don't know } & 3 & 1.53 & 4 & 1.95 \\ \text { Missing } & 9 & 4.59 & 16 & 7.80\end{array}$

Abnormal Pap Smear

$\begin{array}{lllll}\text { Yes } & 14 & 7.14 & 18 & 8.78 \\ \text { No } & 159 & 81.12 & 155 & 75.61 \\ \text { Don't know } & 13 & 6.63 & 15 & 7.32\end{array}$

Table 1 Participant characteristics by vaccination status (Continued)

\begin{tabular}{|c|c|c|c|c|}
\hline \multirow[t]{2}{*}{ Characteristic } & \multicolumn{2}{|c|}{$\begin{array}{l}\text { Vaccinated } \\
(n=196)\end{array}$} & \multicolumn{2}{|c|}{$\begin{array}{l}\text { Not vaccinated } \\
(n=205)\end{array}$} \\
\hline & $N$ & $\%$ & $N$ & $\%$ \\
\hline Missing & 10 & 5.10 & 17 & 8.29 \\
\hline \multicolumn{5}{|c|}{ Birth Control/Contraception } \\
\hline Yes & 128 & 65.31 & 95 & 46.34 \\
\hline No & 59 & 30.10 & 93 & 45.37 \\
\hline Missing & 9 & 4.59 & 17 & 8.29 \\
\hline \multicolumn{5}{|l|}{ HPV infection } \\
\hline Yes & 7 & 3.57 & 10 & 4.88 \\
\hline No & 181 & 92.35 & 178 & 86.83 \\
\hline Missing & 8 & 4.08 & 17 & 8.29 \\
\hline
\end{tabular}

\section{Barriers to HPV vaccination}

The cohort of unvaccinated women was asked a series of questions regarding the barriers they may have faced regarding HPV vaccination. Of the 12 possible barriers presented, the most influential obstacles were a lack of knowledge about the vaccine itself, its potential side effects and cost (Table 2). Only a fraction of the group (3.9\%) was willing to pay the actual cost of the vaccine series, which can vary from $\$ 100$ per dose at its cheapest to $\$ 175$ per dose. Slightly more than half the women in the non-vaccinated group (55.1\%) were willing to pay up to $\$ 100$ for the entire vaccine series, while $10.7 \%$ of this group was unwilling to pay regardless of cost.

Although not influential for the majority of the unvaccinated cohort, the ideas of not requiring the vaccine because the respondent was either in a monogamous relationship or was not currently sexually active were reported as influential for 24 and $29 \%$ of unvaccinated participants, respectively.

\section{Multivariable regression}

The multivariable model compared two subpopulations in the unvaccinated cohort: those who intended to be vaccinated at some point in the future and those who did not.

The univariable analyses indicated that women who intended to be vaccinated had a more positive attitude towards HPV vaccination (lower overall mean score) and were influenced by the vaccine cost and vaccine potential to protect against cervical cancer. Participants who intended to be vaccinated were less likely to perceive cost as a barrier to vaccination. Social norms were particularly influential for the women who intended to be vaccinated, including a belief that if they received a recommendation from a doctor or a parent, or had 

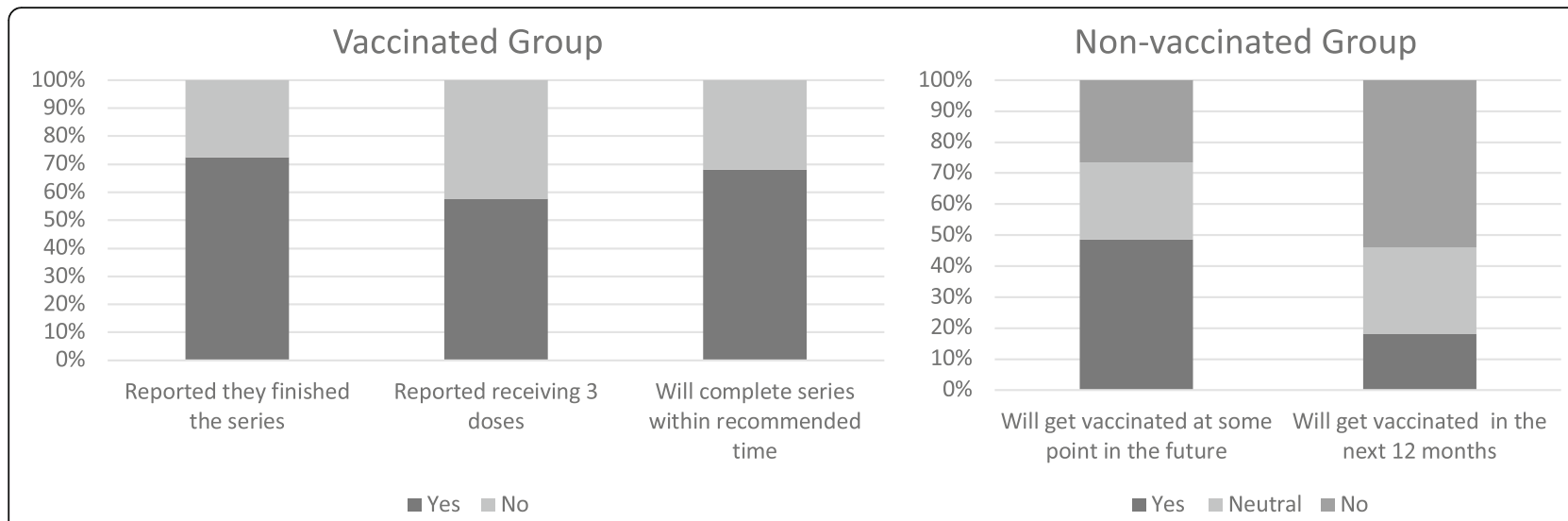

Fig. 1 Vaccination intentions of vaccinated and unvaccinated groups

friends who were getting or who had received the vaccine, they would be more likely to seek out the vaccine. In the final multivariate logistic regression model, only a more positive overall attitude to HPV vaccination and doctor recommendation were significant (Table 3).

\section{Discussion}

The prevalence of HPV vaccination in this study of undergraduate university women was $49 \%$. Both vaccinated and non-vaccinated groups had positive overall attitudes toward HPV vaccination. The biggest barriers

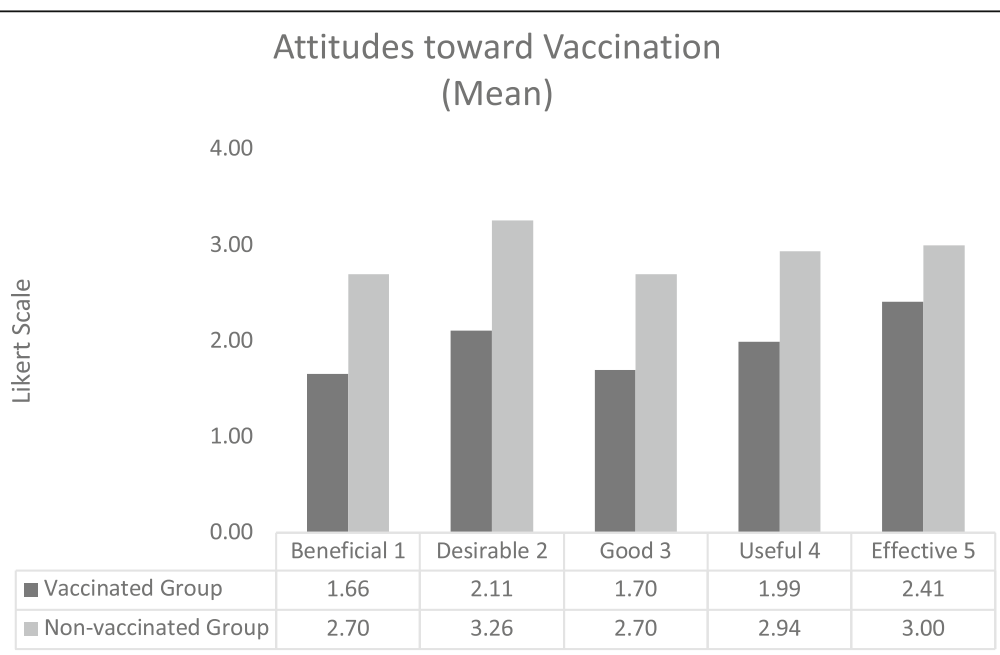

\section{Attitudes toward Vaccination \\ (Median)}

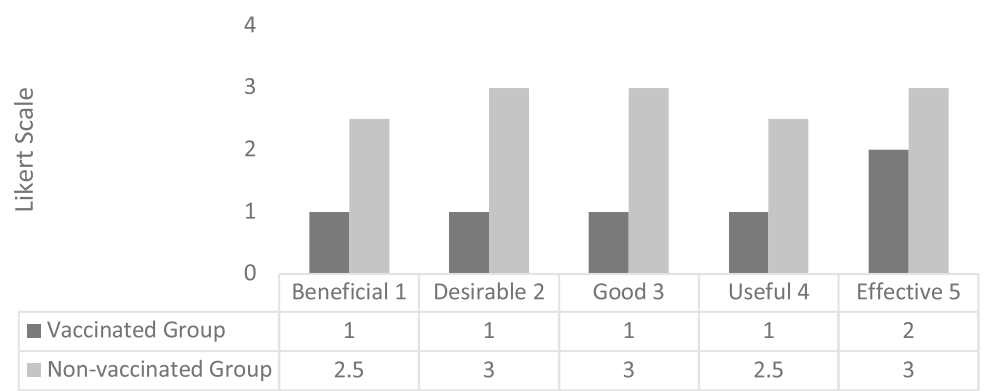

Fig. 2 Attitudes toward HPV vaccination. Legend: Responses are based on a 1 to 7 Likert scale, where a 1 indicates a positive attitude. The scales were rated as ${ }^{1}$ Beneficial to Harmful; ${ }^{2}$ Desirable to Undesirable; ${ }^{3}$ Good to Bad; ${ }^{4}$ Useful to Worthless; ${ }^{5}$ Effective to Ineffective. P-value based on the differences in means 
Table 2 Reported barriers to HPV Vaccination

\begin{tabular}{|c|c|c|}
\hline Barriers & N non-vaccinated group $(n=205)$ & $\%$ \\
\hline \multicolumn{3}{|c|}{ The vaccine costs too much } \\
\hline Influential & 90 & 45.69 \\
\hline Neutral & 24 & 12.18 \\
\hline Not Influential & 60 & 30.46 \\
\hline$N / A^{a}$ & 23 & 11.68 \\
\hline \multicolumn{3}{|c|}{ The vaccine is not covered by my health insurance } \\
\hline Influential & 78 & 39.59 \\
\hline Neutral & 25 & 12.69 \\
\hline Not Influential & 60 & 30.46 \\
\hline N/A & 34 & 17.26 \\
\hline \multicolumn{3}{|c|}{ I don't know enough about the vaccine } \\
\hline Influential & 107 & 54.31 \\
\hline Neutral & 20 & 10.15 \\
\hline Not Influential & 49 & 24.87 \\
\hline N/A & 21 & 10.66 \\
\hline \multicolumn{3}{|c|}{ I don't know enough about the vaccine's potential side effects } \\
\hline Influential & 126 & 66.64 \\
\hline Neutral & 18 & 9.09 \\
\hline Not Influential & 37 & 18.69 \\
\hline N/A & 17 & 8.59 \\
\hline \multicolumn{3}{|c|}{ I don't know if the vaccine works } \\
\hline Influential & 95 & 47.98 \\
\hline Neutral & 35 & 17.68 \\
\hline Not Influential & 53 & 26.77 \\
\hline N/A & 15 & 7.58 \\
\hline
\end{tabular}

${ }^{a} \mathrm{~N} / \mathrm{A}$ : the participant does not think the barrier is applicable to her situation to HPV vaccination found in this study revolved around lack of knowledge about the vaccine and its potential side effects. Cost was an additional important barrier raised by the survey.

The vaccination prevalence in this study is comparable to the few other studies done in similar populations, though these studies were mostly conducted between 2008 and 2010, while our study was conducted in 2013. A study conducted in New York had a prevalence of vaccine series initiation of $56 \%$ [20], while students at a Midwestern university in the United States reported a vaccine series initiation prevalence of 49\% [24]. In Marseilles, secondary and university students reported a prevalence of $35.4 \%$ [25]. These studies found that 70 to $80 \%$ of vaccine initiators completed the entire vaccine series [20, 24, 25]. However, a study conducted at McGill University in Montreal, Quebec, Canada indicated a HPV vaccination prevalence of only $27.3 \%$ [23], which contrasts starkly with our study, while Quebec data from 2010 to 2011 indicated vaccination coverage rates of grade four and nine girls surpassed 75\% [26]. This contrast is likely due to data collection timing, as women at McGill University were not eligible for the free vaccine in elementary or secondary school prior to attending university, indicating the potential need for catch-up vaccination. The present study revealed that a sizeable proportion of unvaccinated women would be interested in receiving the vaccine at some point, which is comparable to the study in Montreal [23]. In the Canadian National Immunization Coverage survey in adults in 2012, $12.2 \%$ of sampled adults younger than 30 reported that they had received an HPV vaccination [27]. In 2014, 45\% of females aged 18-26 and 85 aged 27-45 reported having been vaccinated with at least

Table 3 Comparison of respondents who intended and did not intend to be vaccinated

\begin{tabular}{|c|c|c|c|c|}
\hline \multirow[t]{3}{*}{ Independent Variables: } & \multicolumn{4}{|c|}{ Odds ratio for intention to be vaccinated $(n=99)$, versus no intention to be vaccinated $(n=105)$} \\
\hline & \multicolumn{2}{|c|}{ Univariate Analysis } & \multicolumn{2}{|c|}{ Multivariate Analysis ${ }^{£}$} \\
\hline & OR & $95 \% \mathrm{Cl}$ & OR & $95 \% \mathrm{Cl}$ \\
\hline More negative attitude to HPV vaccination & $0.49^{* * *}$ & {$[0.39,0.63]$} & $0.50^{* *}$ & {$[0.35,0.71]$} \\
\hline Less influenced by vaccine cost & $1.86^{*}$ & {$[1.01,3.40]$} & 1.10 & {$[0.47,2.58]$} \\
\hline Do not know enough about the vaccine & 0.75 & {$[0.41,1.37]$} & 1.20 & {$[0.49,2.92]$} \\
\hline Doctor recommendation & $5.21 * * *$ & {$[2.45,11.09]$} & $4.48^{* *}$ & {$[1.42,14.13]$} \\
\hline Friends got it/were going to get the vaccine & $6.05^{* * *}$ & {$[2.78,13.13]$} & 2.41 & {$[0.94,6.19]$} \\
\hline Susceptibility to HPV & 1.50 & {$[0.81,2.76]$} & 0.73 & {$[0.28,1.91]$} \\
\hline Parent recommendation & $2.31^{*}$ & {$[1.23 .4 .35]$} & 0.70 & {$[0.26,1.86]$} \\
\hline Protect me from developing cervical cancer & $17.35^{* * *}$ & {$[2.23,135.09]$} & 1.08 & {$[0.09,12.45]$} \\
\hline Increased age (per year) & 0.94 & {$[0.81,1.09]$} & 0.81 & {$[0.65,1.00]$} \\
\hline Ethnicity (White vs. not white) & $0.51^{*}$ & {$[0.29,0.90]$} & 0.50 & {$[0.22,1.15]$} \\
\hline
\end{tabular}

Note: Those who did not intend to be vaccinated were used as the reference category $(N=105)$

${ }^{*} p<0.05{ }^{* *} p<0.01{ }^{* * *} p<0.0001$

${ }^{\mathrm{E}}$ Model fit: Hosmer and Lemeshow Goodness-of-fit Test, $p=0.75$ 
one dose of the HPV vaccine [28]. These findings indicate the importance of studies for young Canadian women, for whom a gap in vaccination coverage is evident.

A report from Public Health Ontario on immunization coverage in students found during the 2013-2014 school year, the proportion of vaccination coverage for meningococcus and hepatitis B was 77.5 and $71.5 \%$ respectively in 12-year-olds (age of vaccination), while HPV vaccine uptake was only $61.5 \%$ in 13-year-old girls (age of vaccination) [29]. This indicates a discrepancy in vaccine uptake in school-based vaccination programs, particularly for HPV and the ongoing relevance of catch-up programs, to cover nearly $40 \%$ of girls who are not vaccinated in school.

The Montreal study [23] also explored the relationship of a range of predictors to HPV vaccination intention, finding that negative perceived health consequences, doctor recommendation, attitudes and subjective norms were significant in multivariate analyses comparing unvaccinated women who did not intend to be vaccinated with those who did. Our study found similar results, with overall attitude towards the vaccine and doctor recommendation being significant in the final model. A systematic review assessing the factors associated with HPV vaccination in young women also found that positive vaccine attitudes were related to vaccine uptake [30]. This more favourable view among vaccinated versus non-vaccinated women could be due to increased knowledge about HPV infection, vaccination and vaccine safety, as those with more knowledge were more likely to be vaccinated [30-32].

The main barriers identified by our survey surrounded the topic of lack of vaccine knowledge. Unlike more established vaccines, the long-term side effects of the HPV vaccines are not widely known. These results are not unique to this study, as others also indicated that vaccine novelty, not knowing enough about it or its side effects, are among the chief reasons for university-aged women to not receive the vaccine [33, 34]. There are ongoing studies assessing the safety of the HPV vaccines following their implementation in diverse jurisdictions $[35,36]$. Whilst mild and transient local reactions and systemic effects are commonly reported after vaccination, there is no evidence of a significant association with serious adverse effects, more than a decade after being approved for use in many jurisdictions. This knowledge, however, needs to be clearly communicated to potential vaccine recipients so that they have relevant information available to them on the balance of benefits and potential harms. This emphasizes the importance of knowledge translation strategies, including education by healthcare practitioners and shared decision making [35, 37, 38]. Other factors observed by these studies include being in a monogamous relationship, uncertainty about health insurance coverage and cost $[33,34]$, which were also all noted in our study. In our study, vaccine cost was reported to be an influential barrier in nearly half of the non-vaccinated group. Although many of these women stated that they wished to be vaccinated in the future, the cost of this vaccine series may be part of the reason why they want to defer vaccination to the future, instead of having it immediately. Most women in the unvaccinated group had a favourable opinion of the vaccine, so cost may not have had a large influence on their perception of the vaccine itself, but instead it may play a role in the complexity of prompting attitude and intention into receiving the vaccine.

One way to address barriers related to HPV vaccine knowledge is through a discussion with a family physician or gynaecologist; these providers are prepared to address most questions or concerns about HPV vaccination. The importance of education and health literacy has been highlighted in the literature for various health concerns. Without sufficient knowledge about cervical cancer and the role HPV plays, high vaccination rates may not be achieved. A study in the southern United States noted low vaccination rates among Hispanic women compared to the national rate. Institution of an education program about HPV vaccination and cervical cancer prevention found that knowledge increased after the program and the clinic's HPV vaccination rates tripled [39]. Further, provincial and federal health agencies should consider allowing nurse practitioners and pharmacists to administer the vaccine once someone has the prescription, thereby making receiving it more accessible.

Although many of the unvaccinated women in the study intended to get vaccinated in the future, only a small subset was willing to pay the cost of the vaccine series. This could be enough to prevent intention from becoming behaviour. Clearly cost is not a barrier that can be resolved through education and has been a concern for women in many other studies [33, 34, 40].

In Ontario, a HPV vaccination program was implemented in 2007 specifically for eighth grade girls (ninth grade girls were eligible for the vaccine in the first year of the program only) [41]. This restriction continued until 2012, when the program was expanded to include coverage for all girls up to grade 12, as well as girls from the 2007/2008 cohort, which could be received at a local public health unit [41]. Implications of this restriction are that now, women who were in higher grades at program initiation were not vaccinated and therefore not protected against these HPV strains. These women continue to meet Gardasil's eligibility criteria, but the results of the present study suggest that they are impeded from seeking to be vaccinated by a variety of barriers.

Assessing attitudes about HPV infection, vaccination and cervical cancer prevention has a significant role in 
health promotion and highlights the need for ongoing education about these important health concerns. As seen in many studies, attitudes affect intention to be vaccinated against HPV, while barriers to vaccination include lack of knowledge. It has been reported that increased knowledge can result in people become more receptive to prevention and screening programs or interventions [42]. Our study indicates the ongoing potential role of education in this area and the desire women have for more knowledge regarding their own health care decisions. Our findings indicate that women consider health and the role that healthcare providers play in education and informed healthcare decisions to be important, while elucidating barriers that need to be addressed, not only to improve vaccine uptake but also to affect general health practices. This study highlights the ongoing need for education around HPV, vaccination and cervical cancer, as well as the significant role a catch-up vaccination program can play specifically in this population.

Study strengths include its large and diverse sample. As the questionnaire was created anew, it was appropriate for the population studied. Additionally, the questionnaire was bilingual English/French, eliminating bias that could be introduced from neglecting a sizeable portion of the student population. Finally, this survey included an interesting sample of women: those who were offered the vaccine in schools after it had been introduced in 2007 and those who, due to age requirements, would not have been offered the vaccine.

The main limitation of this study was its response rate of $17 \%$. Nonetheless, this study demonstrated the same proportion of vaccinated women as provincial statistics. Another limitation was the use of self-reported information, which can lead to recall and reporting errors. However, since this was a study of young educated women, this bias is unlikely to strongly influence the results of the study. Another consideration is that while intention to be vaccinated is a predictor of vaccine uptake, it is not the only predictor. Because of the complexity surrounding HPV vaccination uptake, including the perceptions of stigma related to the nature of HPV transmission, the requirement of multiple doses and vaccine cost, the constructs included in the TPB may be limited in fully explaining vaccination uptake.

\section{Conclusions}

This study suggests that nearly half of the unvaccinated women surveyed would be interested in receiving the vaccine in the future, supporting the feasibility of a catch-up HPV vaccination program targeting a similar population. Although cost is not the main barrier preventing HPV vaccination in this population, it is amongst the foremost barriers. By increasing the financial accessibility of the vaccine, as well as focusing on further educating doctors, parents and women themselves on the purpose and benefits of the HPV vaccines, it would seem highly feasible to increase the prevalence of HPV vaccination in Canadian women substantially.

\section{Additional files}

Additional file 1: This is a PDF of the English version of the questionnaire that was administered to the study participants. The data presented in the study was collected and analysed from these questionnaires. (PDF $195 \mathrm{~kb}$ )

Additional file 2: This is a PDF of the French version of the questionnaire that was administered to the study participants. The data presented in the study was collected and analysed from these questionnaires. (PDF $189 \mathrm{~kb}$ )

Additional file 3: The database for the information collected from the survey has also been included as an xls extension. This is the raw data collected from the study questionnaires that was used for analysis. (XLS $501 \mathrm{~kb}$ )

\section{Abbreviations}

Cl: Confidence interval; HPV: Human papillomavirus; OR: Odds Ratio; TPB: Theory of Planned Behaviour

\section{Availability of data and materials}

Spreadsheet of study dataset available in supplementary materials/additional supporting files.

\section{Authors' contributions}

RF developed the survey, analysed and interpreted the data. RF, BP and JL made substantial contributions to the writing of the manuscript. All authors have read and approved the final manuscript.

Ethics approval and consent to participate

This study was approved by the Ottawa Hospital Research Ethics Board (20130038-01H). Written informed consent was completed online by all participants prior to beginning the survey.

\section{Consent for publication}

Not applicable (no individual data presented).

Competing interests

The authors declare that they have no competing interests.

\section{Publisher's Note}

Springer Nature remains neutral with regard to jurisdictional claims in published maps and institutional affiliations.

\section{Author details}

${ }^{1}$ School of Epidemiology and Public Health, University of Ottawa, Ottawa, Canada. ${ }^{2}$ Faculty of Medicine, School of Epidemiology and Public Health, University of Ottawa, 600 Peter Morand Crescent, Room 207G, Ottawa On K1G 5Z3, Canada. ${ }^{3}$ Children's Hospital of Eastern Ontario Research Institute, Ottawa, Canada. ${ }^{4}$ Canada Research Chair in Human Epidemiology, Ottawa, Canada.

Received: 17 May 2016 Accepted: 20 July 2018

Published online: 02 August 2018

References

1. Watts LA, Joseph N, Wallace M, et al. HPV vaccine: a comparison of attitudes and behavioural perspectives between Latino and non-Latino women. Gynecol Oncol. 2009;112:577-82.

2. World Health Organization, WHO Guidance Note: Comprehensive cervical cancer prevention and control: a healthier future for girls and women. http://www.who.int/immunization/hpv/learn/comprehensive_cervical_ cancer_who_2013.pdf (2013). Accessed 2 January 2016.

3. D'Andrilli G, Bovicelli A, Giordano A. HPV vaccines: state of the art. J Cell Physiol. 2010;224:601-4. 
4. Trottier H, Franco EL. The epidemiology of genital human papillomavirus infection. Vaccine. 2006;24(Supplement 1(0)):S4-S15.

5. Koutsky LA, Gallowat D, Holmes K. Epidemiology of genital human papillomavirus infection. Epidemiol Rev. 1988;10:122-63.

6. SOGC. Incidence and Prevalence of HPV in Canada. http://hpvinfo.ca/whatis-hpv/ (2007). Accessed 10 Jan 2016.

7. Bosch FX, Burchell AN, Schiffman M, et al. Epidemiology and natural history of human papillomavirus infections and type-specific implications in cervical neoplasia. Vaccine. 2008;26(Suppl 10):K1-K16.

8. Merck \& Co., Inc. Gardasil 9. https://www.gardasil9.com/ (2017). Accessed 15 Feb 2018.

9. PHAC. Update on the recommended Human Papillomavirus (HPV) vaccine immunization schedule. 2015. https://www.canada.ca/en/public-health/ services/publications/healthy-living/update-recommended-humanpapillomavirus-vaccine-immunization-schedule.html. Accessed 30 July 2018.

10. Medeiros LR, Rosa DD, da Rosa Ml, et al. Efficacy of human papillomavirus vaccines: a systematic quantitative review. Int J Gynecol Cancer. 2009;19: 1166-76.

11. Ali H, Donovan B, Wand $\mathrm{H}$, et al. Genital warts in young Australians five years into national human papillomavirus vaccination programme: national surveillance data. BMJ. 2013;346:F2032.

12. PHAC-NACI. Update on Human Papillomavirus (HPV) Vaccines. http://www phac-aspc.gc.ca/publicat/ccdr-rmtc/12vol38/acs-dcc-1/index-eng.php\#a5 (2012). Accessed 26 Nov 2015.

13. Toft L, Tolstrup M, Müller M, et al. Comparison of the immunogenicity of Cervarix ${ }^{\oplus}$ and Gardasi $^{\oplus}$ human papillomavirus vaccines for oncogenic nonvaccine serotypes HPV-31, HPV-33, and HPV-45 in HIV-infected adults. Hum Vacc Immunother. 2014;10:1147-54

14. PHAC. Recommendations on a Human Papillomavirus Immunization Program. 2007. http://publications.gc.ca/collections/collection_2008/phacaspc/HP40-29-2008E.pdf. Accessed July 2018.

15. Smith L, Brassard $\mathrm{P}$, Kwong J, et al. Factors associated with initiation and completion of the quadrivalent human papillomavirus vaccine series in an ontario cohort of grade 8 girls. BMC Public Health. 2011;11 https://doi.org/ 10.1186/1471-2458-11-645.

16. GlaxoSmithKline. Health Canada Approves Cervarix ${ }^{T M}$, new GSK cervical cancer vaccine. 2010. https://ca.gsk.com/media/594652/final_press_release_ cervarix_en.pdf. Accessed 30 July 2018.

17. Brisson $M, E d m u n d s ~ W$. Economic evaluation of vaccination programs: the impact of herd-immunity. Med Decis Mak. 2003;23:76-82.

18. Cancer Care Ontario. HPV Vaccination. 2012. https://archive.cancercare.on. $\mathrm{ca} / \mathrm{cms} /$ one.aspx? pageld=8194. Accessed July 2018.

19. City of Ottawa. Population. http://ottawa.ca/en/long-range-financial-plans/ economy-and-demographics/population (2015). Accessed January 2016.

20. Bednarczyk R, Birkhead G, Morse D, et al. Human papillomavirus vaccine uptake and barriers: association with perceived risk, actualy risk and race/ ethnicity among female students at a New York State university, 2010 Vaccine. 2011;29:3138-43.

21. Ratanasiripong $\mathrm{N}$. What college women know, think, and do about human papillomavirus (HPV) and HPV vaccine [dissertation]. Kansas City: University of Missouri-Kansas City; 2012.

22. Ajzen I. The theory of planned behavior. Organ Behav Hum. Dec. 1991;50: 179-211.

23. Krawczyk AL, Perez S, Lau E, et al. Human papillomavirus vaccination intentions and uptake in college women. Health Psychol. 2012;31:685-93.

24. Roberts ME, Gerrard M, Reimer R, Gibbons FX. Mother-daughter communication and human papillomavirus vaccine uptake by college students. Pediatrics. 2010;125:982-9.

25. Sabiani L, Bremond A, Mortier I, et al. Évaluation de la couverture vaccinale du vaccin anti-hpv : résultats d'une enquête auprès des lycéennes et étudiantes de la région PACA. J Gynecol Obst Bio R. 2012;41:136-44.

26. INSPQ. HPV Vaccination in Quebec: Knowledge Update and Expert Panel Proposals. https://www.inspq.qc.ca/pdf/publications/1705_VaccVPHQc MAJConnPropComiteExperts_VA.pdf (2012). Accessed November 2015.

27. PHAC. Vaccine coverage amongst adult Canadians: Results from the 2012 adult National Immunization Coverage (aNIC) survey. 2014. https://www. canada.ca/en/public-health/services/immunization/vaccine-coverageamongst-adult-canadians-results-2012-adult-national-immunizationcoverage-anic-survey.html. Accessed July 2018.

28. Government of Canada. Vaccine uptake in Canadian adults: results from the 2014 adult National Immunization Coverage Survey. 2016. https://www. canada.ca/en/public-health/services/publications/healthy-living/vaccineuptake-canadian-adults-results-2014-adult-national-immunization-coveragesurvey.html. Accessed 28 Jan 2017.

29. Ontario Agency for Health Protection and Promotion (Public Health Ontario). Immunization coverage report for school pupils: 2013-14, 2014-15 and 2015-16 school years. Queen's Printer for Ontario, Toronto. 2017.

30. Kessels SJ, Marshall HS, Watson M, et al. Factors associated with HPV vaccine uptake in teenage girls: a systematic review. Vaccine. 2012;30:3546-56.

31. Tung IL, Machalek DA, Garland SM. Attitudes, Knowledge and Factors Associated with Human Papillomavirus (HPV) Vaccine Uptake in Adolescent Girls and Young Women in Victoria, Australia. PloS One. 2016;11 https://doi. org/10.1371/journal.pone.0161846.

32. Coles VA, Patel AS, Allen FL, Keeping ST, Carroll SM. The Association of Human Papillomavirus Vaccination with sexual Behaviours and human papillomavirus knowledge: a systematic review. Int J STD AIDS. 2015;26:777-88

33. Giede C, McFadden LL, Komonoski P, et al. The acceptability of HPV vaccination among women attending the University of Saskatchewan Student Health services. J Obstet Gynaecol Can. 2010;32(7):679-86.

34. Zimet GD, Weiss TW, Rosenthal SL, et al. Reasons for non-vaccination against HPV and future vaccination intentions among $19-26$ year-old women. BMC Womens Health. 2010; https://doi.org/10.1186/1472-6874-10-27.

35. Schurink TM and de Melker HE. HPV vaccination: background information for the Dutch health council. Rijksinstituut voor Volksgezondheid en Milieu RIVM 2017. https://www.rivm.nl/en/Documents_and_publications/Scientific/ Reports/2017/mei/HPV_vaccination_Background_information_for_the _ Dutch_Health_Council. Accessed 30 July 2018.

36. Stokley S, Jeyarajah J, Yankey D, et al. Human papillomavirus vaccination coverage among adolescents, 2007-2013, and Postlicensure vaccine safety monitoring, 2006-2014 - United States. Morb Mortal Wkly Rep. 2014;63:620-4.

37. Thompson EL, Best AL, Vamos CA, Daley EM. "My mom said it wasn't important": a case for catch-up human papillomavirus vaccination among young adult women in the United States. Prev Med. 2017;1-5:1-4.

38. Tudrej BV, Rehman MB, Boussageon R. Improving public health information for patients: shared decision making and influenza vaccination. Br J Gen Pract. 2017;67:421-2.

39. Obulaney PA, Gililand I, Cassells H. Articles increasing cervical Cancer and human papillomavirus prevention knowledge and HPV vaccine uptake through mother/daughter education. J Community Health Nurs. 2016;33:54-67.

40. Bynum SA, Wright MS, Brandt HM, et al. Knowledge, beliefs, and attitudes related to human papillomavirus infection and vaccination, pap tests, and cervical intraepithelial neoplasia among adolescent girls and young women. J S C Med Assoc. 2009;105:267-72.

41. Jantzi-Bauman M. Expansion of the school-based human papillomavirus (HPV) vaccine program.Public Health Wellington-Dufferin-Guelph 2017. https://wdgpublichealth.ca/sites/default/files/file-attachments/basic-page/bh 01.apr0517.r10_-_expansion_of_the_school-based_hpv_vaccine_program_ access.pdf. Accessed 9 Feb 2018.

42. Fernandez ME, Debor M, Candreia MJ, et al. Evaluation of ENCOREplus. A community-based breast and cervical cancer screening program. Am J Prev Med. 1999;16:35-49.

\section{Ready to submit your research? Choose BMC and benefit from:}

- fast, convenient online submission

- thorough peer review by experienced researchers in your field

- rapid publication on acceptance

- support for research data, including large and complex data types

- gold Open Access which fosters wider collaboration and increased citations

- maximum visibility for your research: over $100 \mathrm{M}$ website views per year

At BMC, research is always in progress.

Learn more biomedcentral.com/submissions 